\title{
The Murray-Darling Basin Game - A model to explore water allocation decisions
}

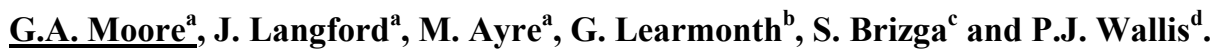 \\ ${ }^{a}$ Melbourne School of Engineering, University of Melbourne; ${ }^{b}$ Systems and Information Engineering, \\ University of Virginia; ${ }^{c}$ Victorian Catchment Management Council; ${ }^{d}$ Monash Sustainability Institute, \\ Monash University. Email: grahamam@unimelb.edu.au
}

The Murray-Darling Basin (MDB) is a very complex socio-ecological system, with a multitude of stakeholders, industries, climates, infrastructure developments, and ecosystems. Human occupation spans back millennia, but within the last two centuries there have been massive changes brought about by a succession of government, community and business actions that have reshaped the environment. It is in such an environment that policy and decision-makers find themselves, in their view, having to plan interventions in a complex and uncertain situation, being unable to foresee the emergent characteristics of their actions.

One proposed way forward in improving aspects of the MDB situation is to create the conditions for social learning among stakeholders in order to achieve changes in understanding that lead to changes in practices. Social learning can be thought of as a process of building mutual understanding and concerted action among stakeholders towards an improved situation. Effective facilitation, or mediation, is an important component of this, and we propose that a stakeholder-constructed game-based modeling platform can act as a mediating object for exploring the outcomes and emergent consequences of water use and management decisions.

We have embarked on an action research project to construct a game-based modeling platform, developed in collaboration with the University of Virginia's UVa Bay Game team, to explore some of the social-technical dynamics of water allocation in the MDB. The Goulburn-Broken Catchment (GBC), in northern Victoria, has been chosen to scope the concept. There are three main research objectives: (1) to construct a robust gamebased modeling platform in the context of the MDB; (2) to engage with a diverse range of stakeholders to decide on key components of the MDB situation to represent in the modeling platform; and (3) to foster reflexivity about the process of model development, game-play and their potential to support practice change among the research team, collaborators and MDB stakeholders.

Firstly, in the UVa game, the overall objectives were condensed to measurable environmental and economic outcomes where land-based players (farmers, land developers, and their associated regulators) took decisions that influenced the amount of nutrients (nitrogen and phosphorous) entering the aquatic system and waterbased players (fishers and regulators). In the MDB, an essential issue of concern to government, consumptive water users and the environment is how to allocate water between different uses. At the macro level, these are consumptive use by people in its various forms and the 'natural' environment.

To-date, the MDB Game consists of a conceptual stocks-and-flows model to keep track of the physical aspects of water, the financial outcomes or stocks of money, and ecosystem outcomes or stocks of natural capital. The flows in the model represent transformations of, for example, irrigation water into a crop and subsequent income or a financial transaction related to water trading activity between consumptive users. The players interface with the model by making management decisions related to their role. Currently there are 5 government authority players, 6 types of consumptive use players and 2 guardian players. Historical or simulated weather and hydrology will be used to drive the underlying processes.

Secondly, we have begun engaging with environmental water managers from the regional level, policymakers and practitioners from the state level, and are planning a workshop hosted by the federal agency tasked with developing a MDB-wide water management plan. This has already led to a shared understanding of the complex dynamics associated with environmental water allocations across these levels of water governance. Finally, the process of contextualizing a game-based modeling platform designed for a different socio-ecological system has inspired reflexive thought about how the MDB situation is framed.

Keywords: Social learning, Water allocation, Simulation game, Complex systems 


\section{INTRODUCTION}

The Murray Darling Basin is a complex social-ecological system. Hydrologically, the river system is dominated by catchment areas on the eastern and south-eastern highlands which feed rivers flowing generally to the west and southwest over vast and mainly semi-arid to arid plains. Prior to European settlement in the early 1800 s, Aboriginal people lived in the basin for at least 40,000 years. During that time it is believed they lived in comparative equilibrium with the biophysical environment. While they may have not developed the means to direct significant amounts of energy to manipulate the topography of the basin, the use of fire and manipulation of water flow is postulated. For example the oral history supports the idea that the Barmah Choke, a channel of the Murray River that traverses a tectonic fault may have been caused by erosion initiated by intervention of the Aboriginal people draining a lake during a flood about 9000 years ago (Atkinson, 2005).

Since European settlement until approximately the mid 1970s, the manipulation of the biophysical and social environment in the southern Murray Darling Basin accelerated vastly. Dams, channels and water control structures now dominate the movement of water across the landscape in all but the largest floods. Various government policies have manipulated the social landscape using the development of infrastructure, economic incentives, and licensing access to water to encourage agricultural and horticultural use of large tracts of land that previously supported only pastoral activities. At the end of this expansionary phase virtually all available dam sites had been exploited and most of annual average catchment water yield had been allocated to agricultural use, resulting in unnaturally frequent and prolonged cease-to-flow events at the mouth of the Murray river. The average flow at Wentworth is around 14,000 GL/y while the surface water use in the late $20^{\text {th }}$ century was around 11,000 GL/y (Murray-Darling Basin Authority, 2010)

Over the last 40 years environmental degradation has become increasingly evident with unprecedented algal blooms on the Darling River, and the die back of iconic River red gum (Eucalyptus camaldulensis) forests (Murray-Darling Basin Authority, 2010). Economic pressures on agriculture can no longer be responded to by making more irrigation water available. The application of chemical, biological and mechanical technology has increased agricultural and labour productivity. Overlaid on this history in which almost all available water was allocated, a drought of record length and intensity occurred.

With this context, successive State and Commonwealth governments have attempted to implement and harmonize policy on water use, environmental protection, and social and economic support of the population of the basin to improve outcomes on all fronts. A key change has been the separation of water property rights from land titles arising from the Council of Australian Governments' Water Reform Framework 1994 (COAG, 1994). Historically, water entitlements were tied to particular parcels of land. As the agricultural economy changed, this meant that water was not necessarily available to the highest value use. By breaking the link between the water property rights and titles, it became possible to trade water to locations and agricultural enterprises that could more effectively use the water. It has also allowed others to buy water for alternative uses. For example, urban populations such as the city of Adelaide can buy water to ensure security of supply, environmental NGOs have purchased water for wetlands, and the governments have purchased water entitlements from agriculture to return water to the river system to deliver environmental benefits.

Major water reforms over the past two decades have led to a situation where governments are developing policy in truly uncharted territory. While the research community has developed some skill at predicting the hydrological response of the entire system to policy changes, there is less certainty about the biological response and poor understanding of the social and economic response. The policy development is also taking place under intense media and political scrutiny where considered discussion of policy options among all stakeholders is difficult. This is exacerbated by the incredibly complex nature of the relationships and interaction between parts of the system components where emergent behaviour is inevitable.

The Basin Game has the potential to be utilised as a facilitation or meditation tool to foster new experiences, cooperative-learning, and reflexive thought ('learning about learning') about decision making for sustainable water management in the Murray-Darling Basin. Social learning is a process of collective performance that involves a convergence of ideas and agreement on a way to progress a situation among multiple stakeholders and is supported by favourable institutional and policy settings (Bommel et al. 2009; Pahl-Wostl et al. 2007; SLIM, 2004). A central part of the practice of social learning is that of 'facilitation', which is required to guide and support learning processes among stakeholders (SLIM, 2004). The Basin Game will play a facilitation or mediation role as a potential 'boundary object' (Star and Greismer, 1989) which allows participants to translate and share their diverse understandings of water management to learn together about the consequences and possibilities of alternative uses. It will do this by enabling collective inquiry amongst players who are responsible for various roles and decisions circumscribed by the Game platform. This 
process of collective inquiry or social learning is critical to the development of new ways of doing water management for more sustainable futures

Pahl-Wostl (2002) explored the concept of decision support systems that involved processes of social learning. The idea of participatory agent-based modeling is introduced as a link between simulation of physical processes and participatory stakeholder engagement (Pahl-Wostl 2002).

\section{GAMES TO EXPLORE COMPLEX SYSTEMS}

In simple situations it is easy to conceive the concept that knowledge precedes action. It follows that if there is enough knowledge, then actions can be designed and implemented with the confidence that the outcome can be easily predicted. Crookall and Thorgate (2009) observe in their editorial in Simulation and Gaming that often the reverse is true. That is action precedes knowledge (or knowing). In complex situations, like the multi-objective problems we are dealing with, knowledge is far from perfect. At the same time, it is not always practical or advisable to learn in the real world because of irreversible consequences. Simulation games are used extensively to allow experiential learning of the participants (Kolb 1984). For example, 'war games' are used to explore outcomes without inflicting casualties or infrastructure damage and 'financial games' are used to learn about markets without having to risk any capital.

In our research, we wish to learn about the relational interactions between people, business and the biophysical environment. We have commenced the development of a multiplayer game, which we hope can be used to facilitate social learning where a range of policy and climate scenarios can be explored. In particular this game is aimed at exploring a "wicked problem" situation, because stakeholders with different world views hold conflicting conceptions of problems, objectives and hence solutions.

\subsection{The UVa Bay Game}

The UVa Bay Game (Learmonth et al., 2011) is a simulation game that simulates the Chesapeake Bay Watershed. It concentrates on decisions that regulators and users make that influence the water quality of runoff from the landscape that impacts on the water quality, the blue crab population of the Bay, and the fishers that rely on a healthy crab population to earn their income. The game allows multiple players to take on specific roles, such as farmers or regulators, to make simulated land-use or statutory decisions and observe the effect of those decisions by way of outputs from a biophysical model of environmental and ecological processes as well as the presumed economic performance of the various roles players.

In the UVa Bay Game the dual objective of balancing environmental sustainability with economic sustainability has been built into the game. The environmental health of the Chesapeake Bay cannot be achieved without sustaining the economic well being of all sectors - farming, land development, and the fishing industry. Consequently, the actions of all decision makers are expressed in environmental impact and financial terms. For example, a land user's decisions are translated into capital and operating costs, while productivity of agriculture is expressed as income based on the market value of the products.

The UVa Bay Game has been used with government policy-makers including the U.S. House of Representatives, the U.S. National Oceanographic and Atmospheric Administration as well as with corporate entities including IBM, General Electric, and Goldman Sachs. NGOs including The Nature Conservancy, the World Resources Institute, and the Chesapeake Bay Foundation have also used the Bay Game. Players are consistently surprised and delighted at how, in a face-to-face, unbiased game environment, they are able to achieve a high level cooperative effort through dialog and information sharing along with the joy of "winning." It is emphasized that "no one wins unless everyone wins," but spirited competition brings about an energetic and productive experience. The post-game debriefing is used to increase appreciation and understanding of the various stakeholder perspectives.

\subsection{The Goulburn Game}

Creating a game for the whole of the Murray Darling Basin (MDB) is the ultimate aim of this research. In order to explore the requirements for the MDB version of the game, it was decided to develop an initial version based on the catchment of a tributary of the Murray River; the Goulburn River. This catchment and the activities within it represent many of the key features of the southern MDB, except for interstate jurisdictional issues around water trading. The roles of some of the players reflect the structure of the Victorian state government departments and authorities, which differ in some respects from the other states.

Figure 1 shows the intended types of players, the types of decisions they would make and the objectives in making those decisions. Three broad objectives were identified: river health, economic prosperity based on 
regional activities centred around agriculture and security of water supply for a major urban community. This contrasts to the Chesapeake Bay Game, which used a water quality and economic objective.

Consumptive use players represent different types of farmers. They vary in their intrinsic nature of water use. Perennial crop irrigators require a high security of supply to ensure that their crops, for example vines or fruit trees, survive from year to year. Annual crop irrigators can tailor their decision as to whether or not to grow a crop on a seasonal or annual basis. In the Goulburn Valley, a dairy farmer growing grass or fodder crops for dairy cows would be a typical annual crop irrigator. They have the option to substitute fodder purchased from other places to maintain their production. Consequently, they can decide to sell part or all of their seasonal allocation of water to other players or can choose to leave it in the reservoir to use the following year. A third group of farmers are those who are within the command area of an irrigation district but do not have a permanent water right. In times when irrigation water is cheap on the market, they may choose to buy water on an opportunistic basis to grow annual crops. Finally, there are irrigation farmers who live outside of the catchment. This group was included to represent the opportunity for water to be traded to geographic locations that may be more favourable for certain crops. A particular feature of this group is that any water they buy may provide some environmental services or cause damage as it is delivered downstream, depending on when, where and over what duration it is delivered. Additional flows to downstream locations may also allow synergistic use by the environmental water holder to create a minor flood to water wetlands by adding extra flow to existing water orders. There may be multiple farmer players of each type, each representing a certain land area of production.

The government players implement policies, which could be varied in different scenarios. The environmental water holder, whose aim is to achieve environmental outcomes by 'irrigating' wetlands or manipulating river flows to achieve ecological outcomes, has similarities to the consumptive use players (i.e. the various types of farmers). The environmental water holder may be a trader in the market who adheres to certain policy rules set by government. The guardian players are there as advocates for the environment on one hand and local communities on the other. While they do not directly use or trade in water, their role is to highlight issues and influence other players.

Figure 2 shows a causal loop diagram (CLD) that with some of the key variables and the relationships between them. The CLD was drawn based on the knowledge of Victorian government catchment managers, water regulators, and a professor of microeconomics, plus the combined knowledge of the authors. To read the CLD, take any two boxes and an arrow joining them. The arrow depicts a positive relationship if an increase in the magnitude of the variable in the source box causes an increase in the magnitude of the variable in the target box, or if a decrease in the source causes a decrease in the target. The arrow depicts a negative relationship if an increase in the source results in a reduction in the target. For example, an increase in water stored in the reservoir will allow or cause more irrigation consumptive use because the price of water will go down. On the other hand, an increase in irrigation will cause the amount of water in storage to decrease, since it has been used. The CLD is used to brief the players about the underlying behaviour of the game. As part of the action research, new loops may be added to the CLD and the underlying game algorithms

The game engine is essentially a stocks and flows dynamic simulation that keeps track of water in its various forms as time progresses through the seasons. Water is added to the game via stochastically generated or historical rainfalls and stream flows. Water leaves the game via consumptive use, for either agriculture or the environment, and via required flows to downstream uses. Hydrological routing to achieve this will use the Goulburn System Model based on the REALM (DSE, 2011). Farm production models are used to transform irrigation water into economic benefit. Production functions based on Australian Bureau of Agricultural and Resource Economics and Sciences (ABARES) irrigation farm data will be used to relate water use decisions to agricultural production (Hughes, 2011). It is assumed that a change in production by game players does not impinge on prevailing commodity prices that are largely determined by global forces. Commodity prices are set as part of the scenario initialisation. River health outcomes are determined by the duration, height, and season of flow in environmentally significant features of the river and flood plains such as wetlands, deep pools, and riffles of the Goulburn River (Cottingham, 2003).

The UVa Bay Game uses a time step of two years between decisions by the players. This is appropriate because of the nature of the decisions about capital expenditure or agricultural production that heavily influence the environmental outcomes and the time scale of environmental impacts. In the Goulburn Game, a different approach will be required because one of the dominant inputs will be simulated or historical weather data and the time-frame for decisions such as farmers buying and selling water, or environmental water holders releasing environmental flows tends to be measured in weeks rather than years. These short-term 
decisions need to be coupled with longer-term regulatory decisions, which may be current for five to ten years.

\section{The Goulburn Game to explore water allocation \& use, policy \& practice}

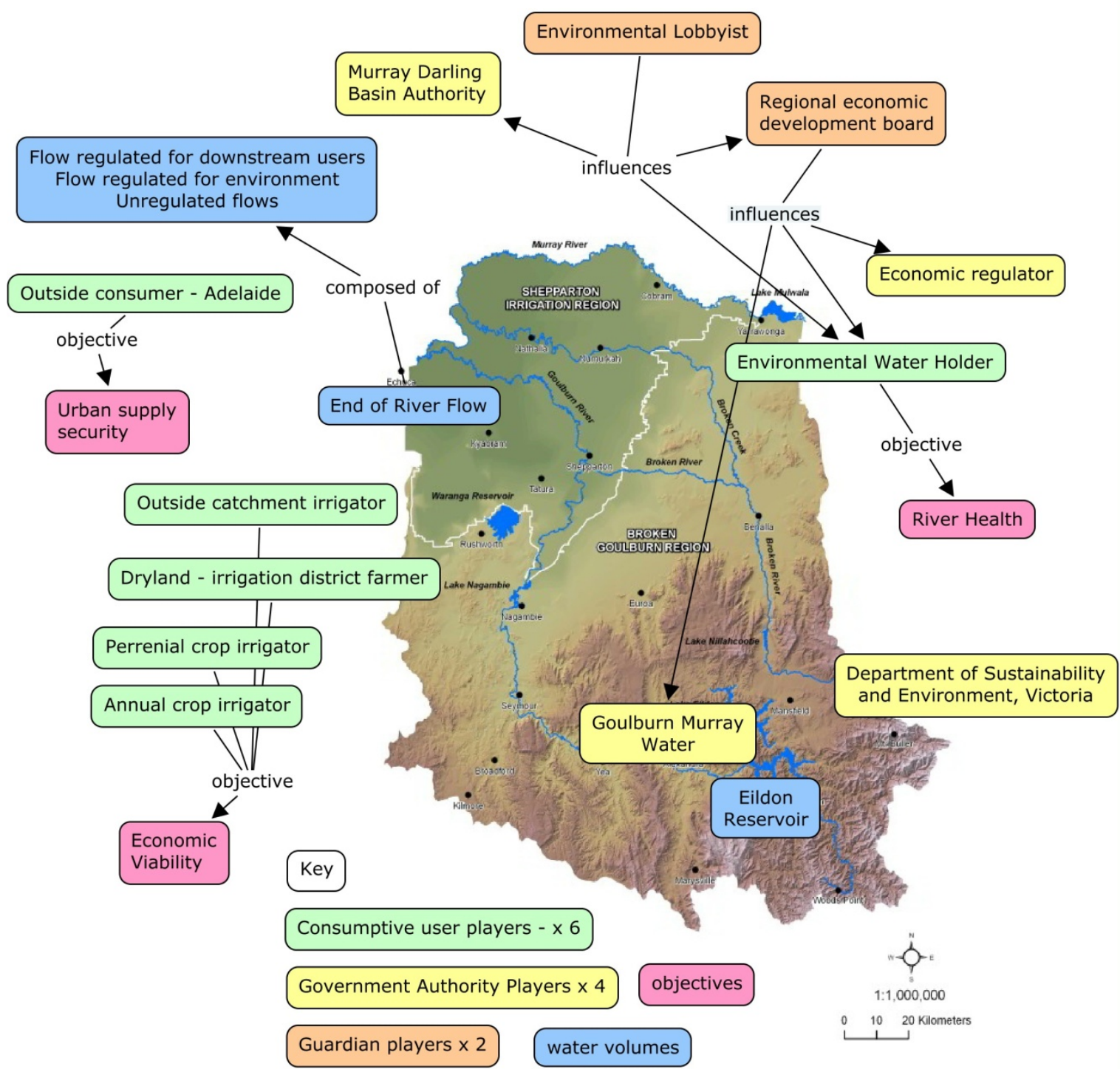

Figure 1. The players, objectives and water volumes used in the Goulburn Game. (Background image source: Goulburn Broken Catchment Management Authority)

\section{PLAYING THE GAME FOR SOCIAL LEARNING}

Interactive modelling has been used to promote stakeholder dialogue around reducing riverine nitrogen loads in the Upper Svartå River basin in Sweden (Andersson 2004). In this case, model outputs of different scenarios were introduced into discussion panels comprised of farmers, technical advisors, bureaucrats and politicians. The dialogues lead to group learning processes and the emergence of a shared understanding and shared responsibility. 


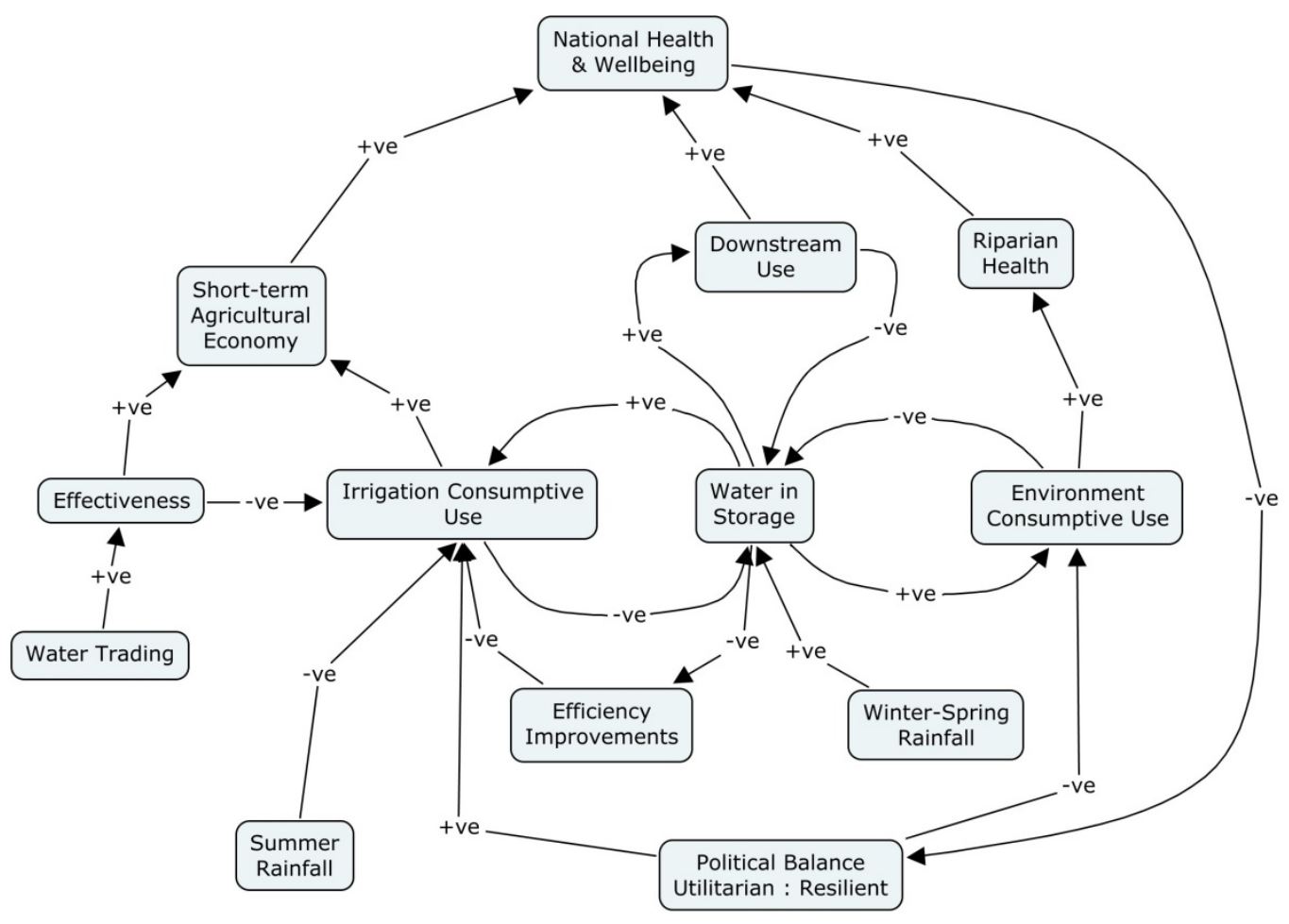

Figure 2. A causal loop diagram showing the relationships between the key uses, water storage and national outcomes.

In the Basin Game, sustainability is considered an emergent property resulting from relational activity between stakeholders, rather than a specific state of the system. This is also true in the real world, although policy makers often regard sustainability as a fixed target or state. The Basin Game has the potential to mediate real-world learning between stakeholders in order to create a performance from which sustainability can emerge.

Theories of social learning emphasise the value of social networks in generating change responses including innovations in knowledge, practice and policy reforms. Recent analyses of integrated water resource management and natural resource management argue for a community-driven approach to planning and development, where social learning is key to developing responses to complex problems (Lane and Robinson 2009).

Through an action research method of inquiry, we will engage participants in the Basin Game as 'players' from different 'communities of practice' (Wenger 1998) in catchment management. A model of stakeholder engagement based on 'communities of practice' recognises the need to engage the everyday, routine practices of people and institutions in determining options for future water management. We understand the Basin Game as a platform for change (Boxelaar 2004) for improved catchment management that involves people and their institutions and practices in a collective inquiry and enactment (performance) to inform a deliberative approach to change (Friedman and Rogers, 2007). An interesting early observation is that the definition of stakeholders needs to be broad and inclusive. It is important that people who nominate the stakeholders include themselves, rather than think stakeholders are just the recipients of decisions, goods, and services. The components of the Basin Game modelling platform will be identified and designed through iterative engagements with stakeholders in the case study catchment and the Murray-Darling Basin generally. We have already begun this process of deliberative, participatory design through strategic conversations in 2011 with government environmental and consumptive water managers and with the federal agency responsible for water reform in the Murray Darling Basin.

\section{CONCLUSIONS}

The Murray Darling Basin is a very complex system that presents a major challenge to policy- and decisionmakers. At a time of transition of management arrangements and as increasing information about potential impacts of the climate change emerge our knowledge of how these will interact with the population and the biophysical environment that are dependent on the water fluxes in the basin requires further improvement. 
The concept of using a simulation game to allow experiential learning by the stakeholders about the behaviour of each other and the system as a whole is presented. The research builds on experience of a simpler scenario with simpler objectives and relatively long time steps to create a simulation game with more complex objectives and much shorter time steps. The primary goal of the game is promote social learning of the players and the system, while a secondary goal is to discover emergent properties of the system that arise from the interaction of human behaviour and the underlying biophysical system.

\section{REFERENCES}

Andersson, L. (2004). 'Experiences of the use of riverine nutrient models in stakeholder dialogues', International Journal of Water Resources Development, 20, 399-413.

Atkinson, W. (2005). Yorta Yorta Occupation and the search for common ground. Proceedings of the Royal Society of Victoria, 117 (1), 1-22.

Bommel, S.V., N. Röling, N. Aarts, and E. Turnhout (2009). Social learning for solving complex problems: a promising solution or wishful thinking? A case study of multi-actor negotiation for the integrated management and sustainable use of the Drentsche Aa area in the Netherlands. Environmental Policy and Governance, 19, 400-412.

Boxelaar, L. (2004). Diversity and convergence in platforms for change: Building social capability for land management. PhD Thesis. Institute of Land and Food Resources. Melbourne, University of Melbourne.

COAG (1994). Communique. Council of Australian Governments: Hobart, 25 February 1994.

Cottingham, P., M. Stewardson, D. Crook, T. Hillman, J. Roberts, and I. Rutherfurd (2003). Environmental flow recommendations for the Goulburn River below Lake Eildon. CRC Freshwater Ecology and CRC Catchment Hydrology. Technical Report 01/2003.

Crookall, David and Thorngate, Warren (2009). Acting, Knowing, Learning, Simulating, Gaming. Simulation Gaming, 40 (1), 8-26.

DSE (2011). Resource Allocation Model (REALM). http://www.water.vic.gov.au/monitoring/surface-watermodeling/realm Accessed 26 September 2011.

Friedman, V.J. and T. Rogers (2007). Action science: Linking causal theory and meaning making in action research. In Reason, P.W. and H. Bradbury (Eds.) The SAGE Handbook of Action Research: Participative Inquiry and Practice 2nd ed., Sage Publications.

Hughes, N. (2011). Estimating irrigation farm production functions with ABARES survey data ABARES conference paper 11.01 Australian Agricultural and Resource Economics Society. 9-11 February 2011, Melbourne, Victoria.

Kolb, D.A. (1984). Experiential learning : experience as the source of learning and development. Englewood Cliffs, N.J., Prentice-Hall.

Lane, M.B. and C.J. Robinson (2009). "Institutional Complexity and Environmental Management: The Challenge of Integration and the Promise of Large-scale Collaboration. Australasian Journal of Environmental Management. 16, 27-35.

Learmonth, G., D. Smith, W. Sherman, M. White, and J. Plank (2011). "A practical approach to the complex problem of environmental sustainability: The UVa Bay game ${ }^{\circledR}$." The Innovation Journal: The Public Sector Innovation Journal, 16 (1), Article 4.

Murray-Darling Basin Authority (2010). Guide to the proposed Basin Plan: overview, Murray-Darling Basin Authority, Canberra.

Pahl-Wostl, C. (2002). Towards sustainability in the water sector - The importance of human actors and processes of social learning. Aquatic Sciences, 64, 394-411.

Pahl-Wostl, C, M. Craps, A. Dewulf, E. Mostert, D. Tabara, and T. Taillieu, (2007). Social learning and water resources management. Ecology and Society, 12 (2), 5.

SLIM (2004). Social Learning as a Policy Approach for Sustainable Use of Water: A field tested-framework for observing, reflecting and enabling, SLIM (Social Learning for the Integrated Management and Sustainable Use of Water at Catchment Scale) Framework (accessed at http://slim.open.ac.uk).

Star, S. and Greismer, J. (1989). 'Institutional ecology, 'translations' and boundary objects: amateurs and professionals in Berkeley's Museum of Vertebrate Zoology, 1907-39', Social Studies of Science, 19, 387420.

Wenger, E. (1998), Communities of Practice: Learning, Meaning and Identity, Cambridge University Press, Cambridge. 